\title{
Influences of shaker armature dynamics on periodic force measurement
}

\author{
Saher R. Hassan ${ }^{1,2}$, Ch. Schlegel ${ }^{1}$, R. Kumme ${ }^{1}$ \\ ${ }_{1}^{1}$ Physikalisch-Technische Bundesanstalt, Bundesallee 100, 38116 Braunschweig, Germany \\ ${ }^{2}$ National Institute for Standards (NIS), Giza, Egypt
}

\section{ABSTRACT}

In this article, we investigate the influence of the shaker armature's mechanical structure on periodic force measurement, with particular emphasis on measurement uncertainty. In order to perform modal and harmonic analyses of the measurement setup, a finite element model was iteratively developed. The model was validated by measurements with a scanning vibrometer. The results show that the dynamic behaviour of the shaker armature should be taken into consideration before carrying out a periodic force measurement.

\section{Section: RESEARCH PAPER}

Keywords: Dynamic force; periodic force calibration; shaker armature.

Citation: Saher R. Hassan, Ch. Schlegel, R. Kumme, Influences of shaker armature dynamics on periodic force measurement, Acta IMEKO, vol. 8, no. 3, article 8, September 2019, identifier: IMEKO-ACTA-8 (2019)-3-8

Editor: Dušan Agrež, University of Ljubljana, Slovenia

Received February 22, 2018; In final form July 19, 2019; Published September 2019

Copyright: This is an open-access article distributed under the terms of the Creative Commons Attribution 3.0 License, which permits unrestricted use, distribution, and reproduction in any medium, provided the original author and source are credited.

Corresponding author: Saher R. Hassan, e-mail: saher.r.hasan.ext@ptb.de

\section{INTRODUCTION}

The measurement of dynamic force is widely used in many industrial applications, such as material testing, production processes, and vehicle dynamics. Therefore, a number of national metrology institutes have developed periodic force calibration facilities [1]-[3]. The dynamic behaviour of a periodic calibration is affected by three main factors: the internal structure of the force transducer; the mechanical coupling between the transducer and the shaker armature on one side and between the transducer and the top mass on the other side; and the dynamic behaviour of the shaker armature. The former factor introduces a periodic input excitation force to the base of the force transducer. This force is directly connected to the shaker armature's dynamic parameters. The main goal of the calibration process is to estimate the dynamic parameters of the force transducers, such as stiffness and damping, in addition to their dynamic sensitivity. The stiffness $k_{f}$ and damping $b_{f}$ of the force transducer can be estimated according to Equation (1) [4], which describes the force transmissibility function.

$$
\frac{\ddot{y}_{f}}{\ddot{y}_{s}}=\sqrt{\frac{1+\left(\frac{b_{f}}{k_{f}} \cdot \omega\right)^{2}}{\left(1-\frac{m_{t}}{k_{f}} \cdot \omega^{2}\right)^{2}+\left(\frac{b_{f}}{k_{f}} \cdot \omega\right)^{2}}}
$$

where $\ddot{y}_{f}$ and $\ddot{y}_{s}$ are the measured acceleration values of the load mass attached to the force transducer and the shaker armature, respectively. $m_{t}, k_{f}$, and $b_{f}$ are the top mass, stiffness, and damping coefficient of the force transducer, respectively.

These parameters can be estimated only if the acceleration is measured at two points: on the top of the load mass and at the base of the force transducer. One of the main limitations of this approach is that the measurement of the acceleration at the base of the force transducer is actually performed on the shaker armature and not directly under the force transducer. This actual acceleration measurement is affected by the acceleration distribution over the shaker armature.

So far, research has tended to focus either on the modal analysis of the measurement setup with the assumption of a lumped mass shaker armature [5] or on the force transducer only without the shaker and the load mass [6]. To investigate the dynamic behaviour of the complete mechanical structure of a periodic force measurement setup, a Finite Element (FE) model has been developed and verified to carry out the modal and harmonic analyses. The model takes the complete mechanical structure of the setup into consideration, including the force transducer, load mass, and shaker armature as in a real application. 


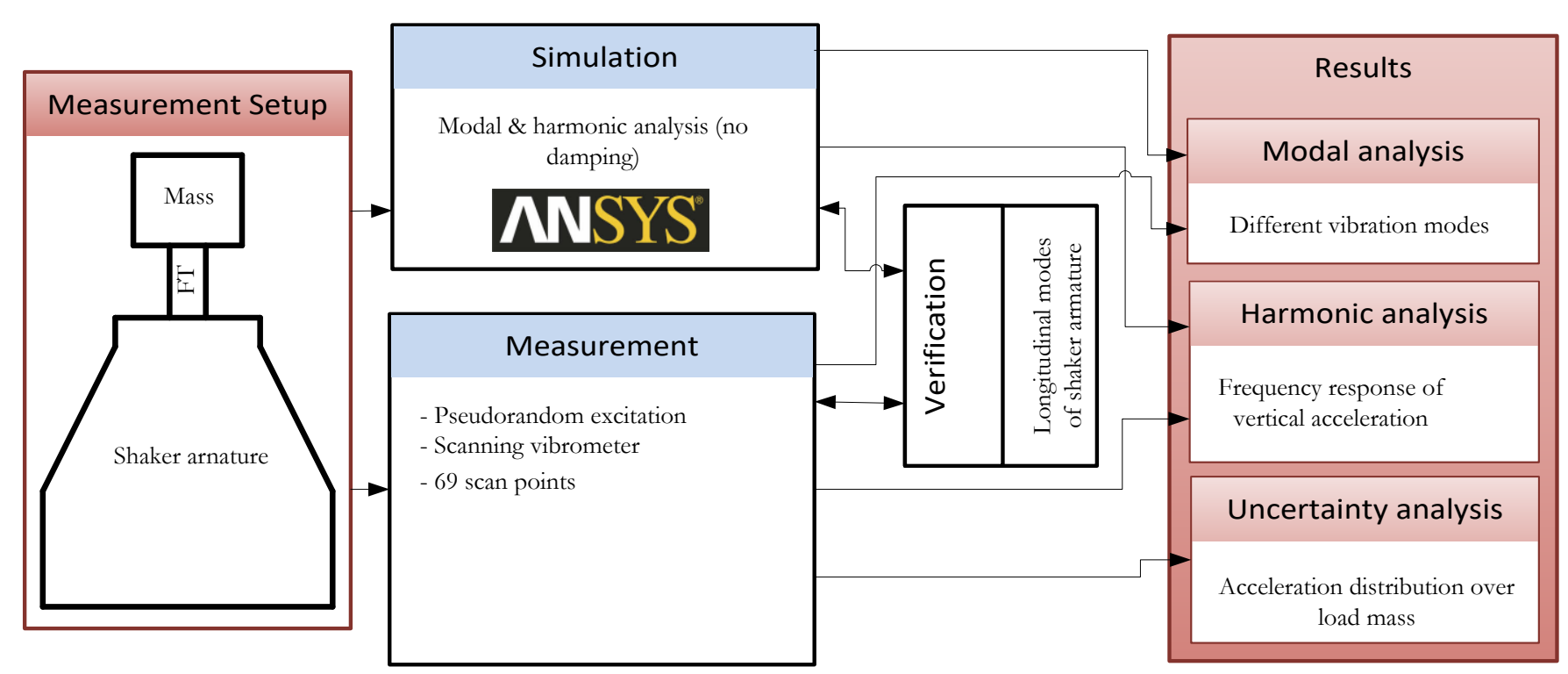

Figure 3. A flow diagram showing the methodology of the work.

\section{METHODOLOGY}

A flow diagram of the procedure that has been followed to undertake this research is illustrated in Figure 3, which was first published in [7].

A photograph of the mechanical portion of the experimental arrangement is provided on the left-hand side of Figure 1, while a $3 \mathrm{D}$ model of the mechanical structure is shown on the righthand side of the same figure. More details about the measurement setup can be found in [8]. A $100 \mathrm{~mm}$ high hollow aluminium bar was used as a force transducer. The bar's outer diameter is $26 \mathrm{~mm}$, with a wall thickness of $2 \mathrm{~mm}$. The bar was mounted onto the shaker armature using a mechanical thread adapter. A $80 \mathrm{~mm}$ diameter and a $97 \mathrm{~mm}$ high brass cylinder with a mass value of about $4 \mathrm{~kg}$ was used as a load mass. This load mass has a threaded hole in the centre at one end, which is attached to the bar using a mechanical thread adapter. The vertical acceleration was measured at 69 points. These points are distributed over the entire top surface of the load mass, as shown in Figure 1. Pseudorandom excitation was applied to the shaker with a predetermined frequency range and amplitude in order to obtain the frequency response of the whole mechanical structure. As the acceleration distribution is only measured on top of the load mass by measuring the vertical acceleration, only the modes that have longitudinal displacement/acceleration

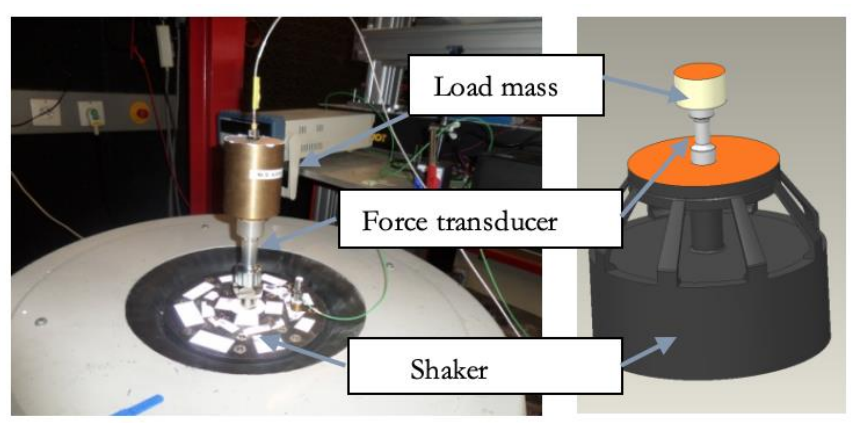

Figure 1. Photograph of a periodic measurement setup (left) and the 3D model (right). components can be detected.

An FE model has been developed to perform the modal and harmonic analyses of the complete mechanical structure of the periodic force measurement setup. The mechanical structure includes the force transducer, load mass, and shaker armature. The mechanical properties of the three parts were taken from tabulated data. All threaded connections were assumed to be rigid. Since the estimation of the damping coefficient is not a focus of this study, the FE model assumes the absence of damping; therefore, it is predicted that a steep frequency response curve and relatively high resonance amplitudes will occur.

To perform modal analyses for all possible vibration modes, fixed boundary conditions were provided at the base of the shaker armature, without any other boundary conditions on the rest of the structure. Harmonic analysis was performed by adding harmonic excitation signals to the base of the shaker armature. The frequency response of the averaged acceleration on the top surface of the load mass was visualised in order to simulate the real measurement setup as realistically as possible and obtain comparable results. A comparison between the measured and simulated longitudinal resonances of the shaker armature has been used to verify the FE model proposed. ANSYS software was used to perform the FE calculations.

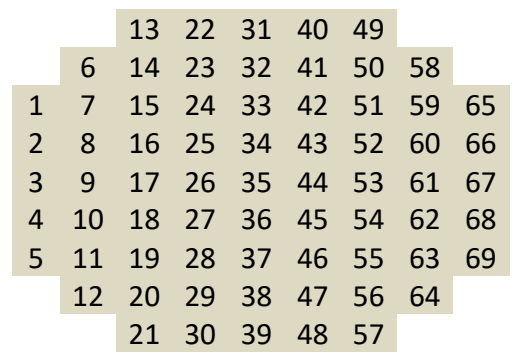

Figure 2. Distribution of the scan points on the load mass. 69 points are uniformly distributed over the load mass surface. The scanning vibrometer measures the vertical acceleration of each point. 


\section{RESULTS AND DISCUSSION}

The results are introduced in this section in the following order: verification of the FE model, modal analysis, and harmonic analysis.

\section{Verification of FE model}

Figure 4 (top) represents the longitudinal mode of the shaker armature using the FE model. The simulated resonance frequency of the shaker armature is $2481.3 \mathrm{~Hz}$, and it deviates about $1.3 \%$ from the measured resonance frequency.

Figure 4 (bottom) shows the measured frequency response using pseudorandom excitation in the range of $0-10 \mathrm{kHz}$. As can be seen in Figure 4 (bottom), the measured resonance frequency is $2450 \mathrm{~Hz}$.

\section{Modal analysis of the measurement setup}

Figure 5 shows the spatial displacement for the different dynamic modes of the simulated setup in the range of $0-2,600$ Hz. These modes can be categorised into tilting, torsion, and longitudinal modes.

In titling modes, one element of the structure (e.g. load mass) tilts relative to the other two elements. The first and second modes show that the load mass tilts relative to the force transducer. The 4th, 5th, 8th, and 9th modes represent the tilting of both the load mass and the force transducer relative to each other. The tilting of the shaker armature is represented in the 10 th and 11 th modes.

In torsion modes, there is a difference in the spatial
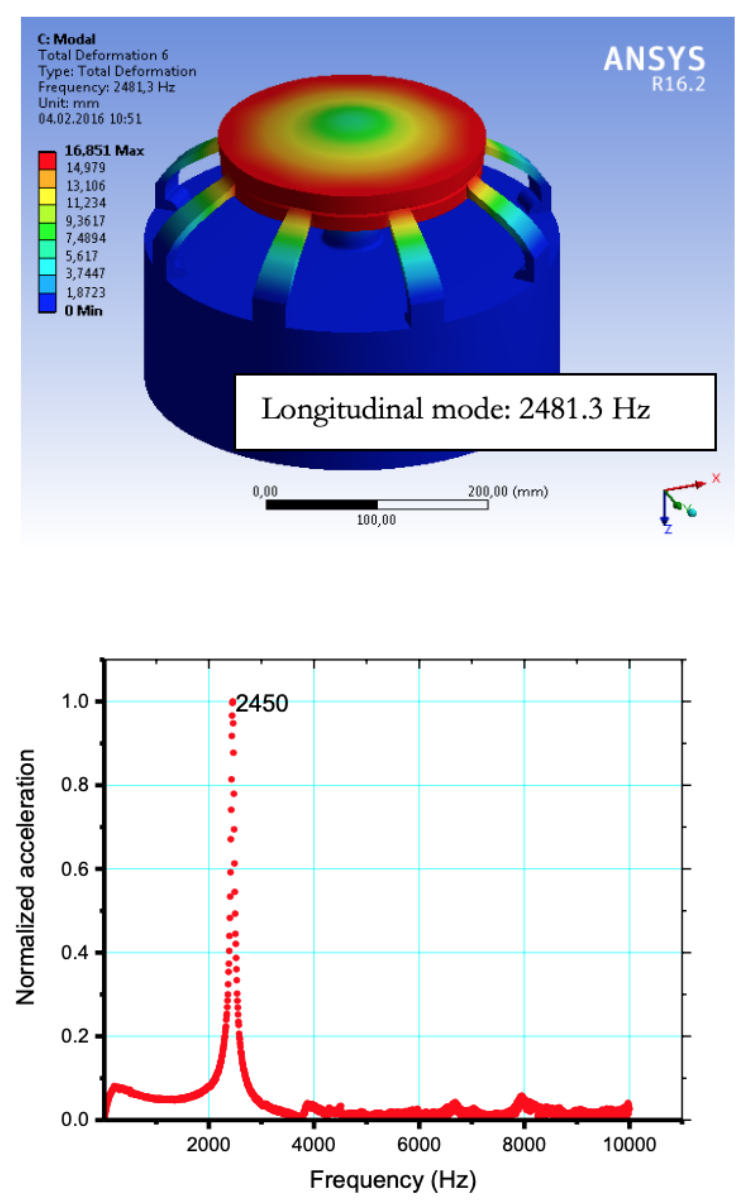

Figure 4. The FE modal analysis of the shaker armature with the longitudinal resonance (top) and the measured frequency response (bottom). displacement over the radial direction of either the load mass (as shown in the 3rd mode) or the shaker armature (as shown in the 6th mode).
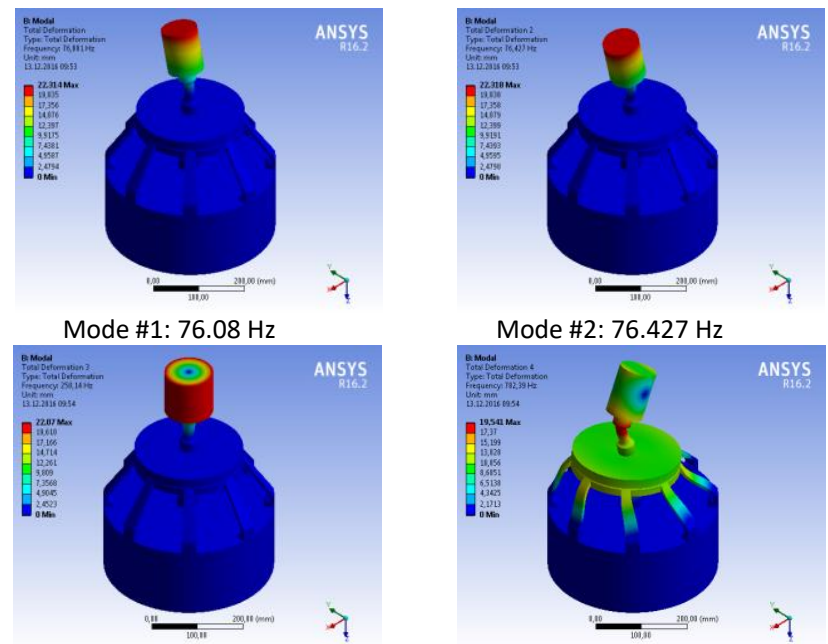

Mode \#2: $76.427 \mathrm{~Hz}$

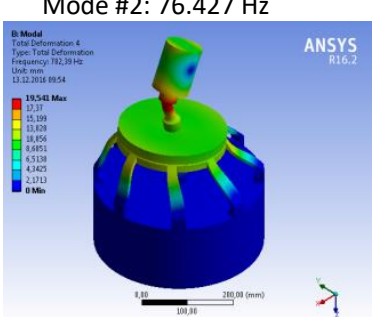

Mode \#3: $258.14 \mathrm{~Hz}$

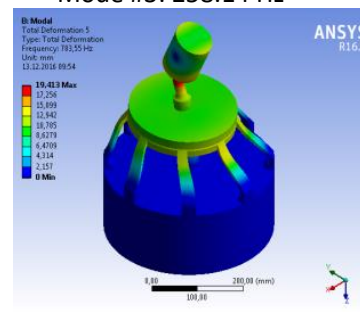

Mode \#4: $782.39 \mathrm{~Hz}$

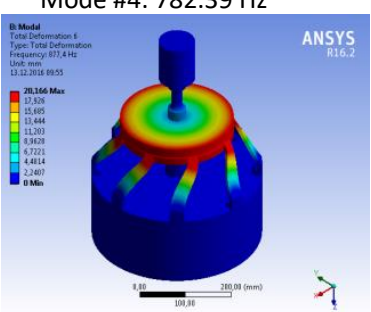

Mode \#5: $783.55 \mathrm{~Hz}$

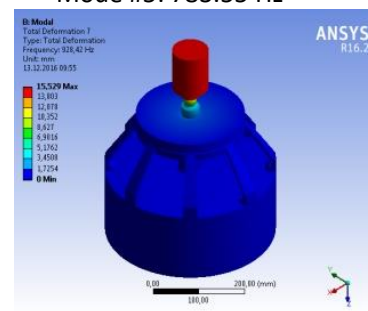

Mode \#7: $928.42 \mathrm{~Hz}$

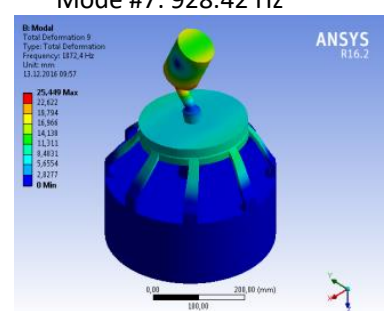

Mode \#9: $1072.4 \mathrm{~Hz}$

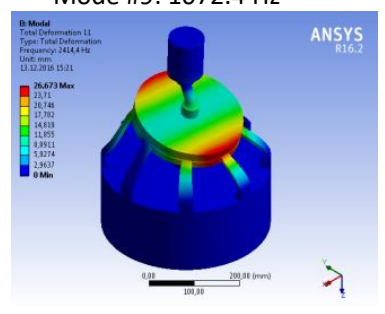

Mode \#11: $2414.4 \mathrm{~Hz}$

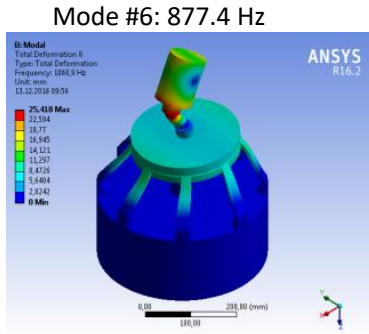

Mode \#8: $1068.9 \mathrm{~Hz}$

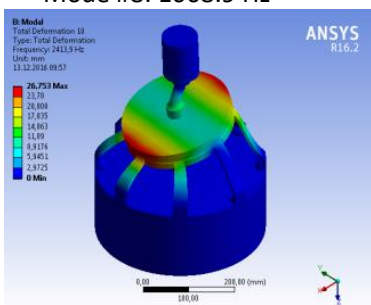

Mode \#10: $2413.9 \mathrm{~Hz}$

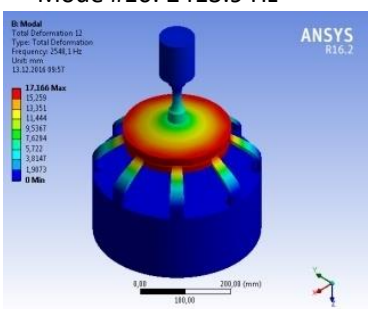

Mode \#12: $2540.1 \mathrm{~Hz}$

Figure 5. FE modal analysis of the complete measurement setup including force transducer and load mass mounted on the shaker armature. The analysis contains 12 modes in a frequency range of $0-2600 \mathrm{~Hz}$. The colour code gives the displacement values whereby red indicates high displacement and blue indicates zero displacement. Note the exaggeration of the displacement values. 
Vertical displacement/acceleration components are assumed to be close to zero in the torsion modes.

Two longitudinal modes (main system resonances) have

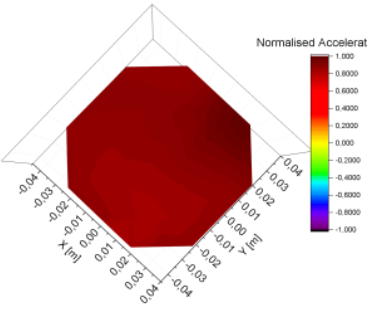

$288 \mathrm{~Hz}$ : Torsion mode

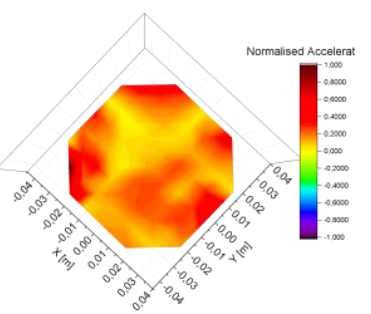

$731 \mathrm{~Hz}$ : Tilting mode

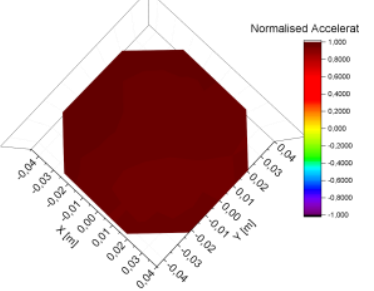

$950 \mathrm{~Hz}$ : Longitudinal mode

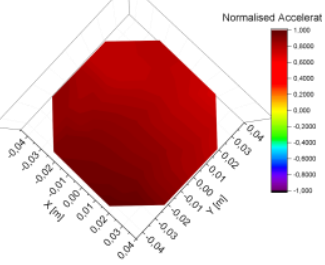

$2488 \mathrm{~Hz}$ : Longitudinal mode

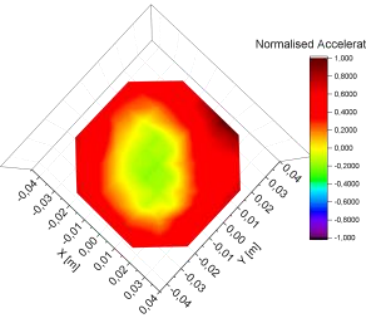

$456 \mathrm{~Hz}$ : Tilting mode

$787 \mathrm{~Hz}$ : Tilting mode

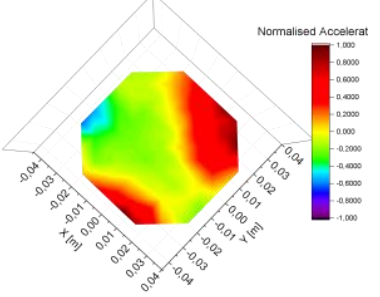

$1069 \mathrm{~Hz}$ : Tilting mode

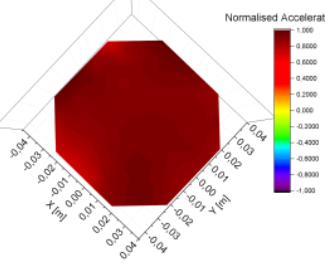

$294 \mathrm{~Hz}$ : Normal frequency

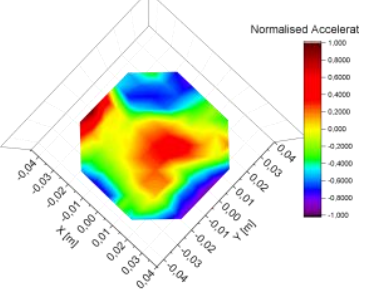

been noted. The first resonance, which corresponds to the force transducer, appears in the 7th mode, and the second one, which corresponds to the shaker armature, appears in the 12th mode.

Figure 6 shows the vertical acceleration distribution over the load mass at certain frequencies (written below each figure). These frequencies were selected where certain modes can obviously be observed. The acceleration values are normalised to the maximum positive acceleration value at each frequency status. There is a significant dispersion of the vertical acceleration distribution of the tilting modes rather than longitudinal modes and normal operating frequencies; thereby, a good agreement has been achieved between the measured and the simulated results.

\section{Harmonic analysis}

Figure 7 shows the measured and simulated frequency resonance of the complete structure. The results show a good agreement between the simulated and measured resonance frequencies of the system, with a deviation of about $2.3 \%$.

Figure 7 (bottom) reveals that there has been a sharp drop in the FE model amplitudes far from the resonances caused by the assumption of an absence of damping in the FE model. The consideration of damping in the FE model might not significantly improve the results, as the aim of the study is to detect the position of different vibration modes to prevent
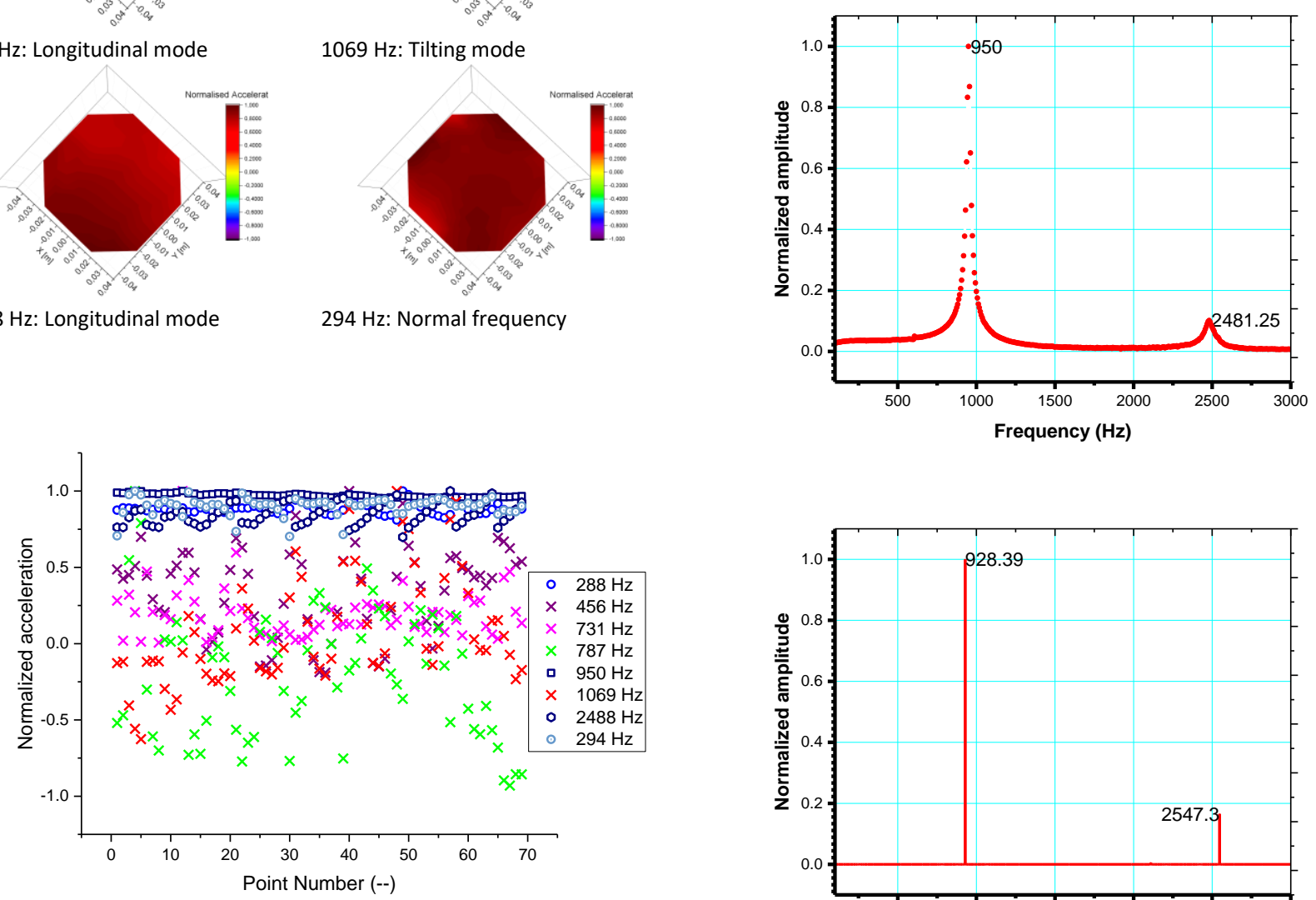

Figure 6. Normalised measured vertical acceleration distribution on the load mass of different frequencies (top), showing high variations for tilting modes (bottom). Crosses represent tilting modes, while circles and squares represent the other modes. The values of acceleration are normalised to the maximum positive values in each frequency status.
Figure 7. Harmonic analysis in the range of $0-3,000 \mathrm{~Hz}$ of the measurement setup using the FE model due to harmonic excitation in the longitudinal direction (bottom) and the measured acceleration resonance over the load mass using pseudorandom excitation (top). 


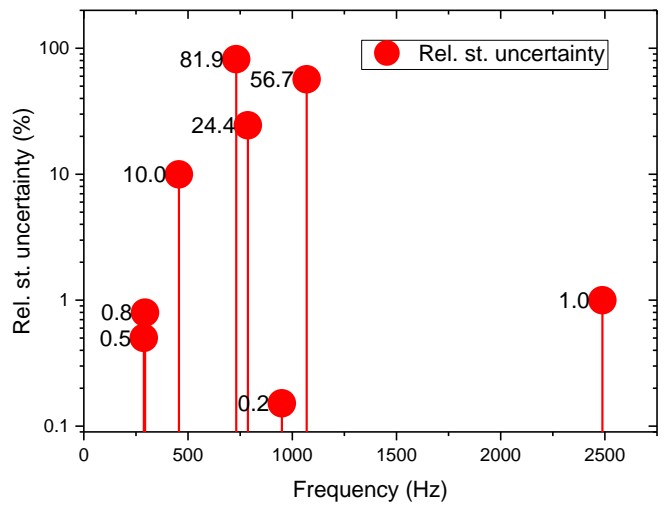

Figure 8 . The relative standard uncertainty of the measured acceleration on the top of the load mass. The uncertainty was obtained by averaging 69 acceleration measuring points. In addition, note the log scale of the $y$-axis.

these modes during the calibration of dynamic force transducers. Another reason is that the materials of the system components are metals, which have a light damping coefficient.

Compared with the second resonance, the first resonance (which represents the fundamental frequency of the force transducer) exerts higher amplitudes stemming from the measurement/visualisation of the frequency response over the load mass. It is almost certain that the second resonance (which represents the shaker's resonance) amplitude would be higher than that of the first resonance if the frequency response were measured/visualised on the top surface of the shaker armature.

\section{Uncertainty analysis}

It is obviously predicted that the calibration of force transducers within the tilting modes will lead to higher contributions of type A uncertainty, and hence, the expanded uncertainty will significantly increase. It is well known that the main uncertainty contribution in the periodic force calibration of force transducers comes from the acceleration measurement of the load mass [9]. Figure 8 shows the relative standard uncertainty of the measured acceleration on the top surface of the load mass at the same selected frequencies as in section 3.3.

It should be noted that the uncertainty given above does not include the contribution influenced by the measuring equipment.

A typical calibration of a dynamic force transducer is shown in Figure 9. The calibration has been performed according to the procedure outlined in [1] using two different load masses, 2 and $\mathrm{kg}$, with the corresponding expanded uncertainty of the individual sensitivity points. The results show the effect of the tilting modes on the resulting uncertainties. In addition, the variation in the acceleration distribution at the top of the load mass increases after resonance (around $1 \mathrm{kHz}$ ) of the applied load masses due to the increasing effect of the rocking modes within higher frequencies.

\section{CONCLUSIONS}

In this article, the mechanical influences of the shaker armature on the periodic force measurement have been thoroughly investigated. Because the investigations have been performed through the establishment of a measurement setup and a new FE model proposal, the following conclusions can be drawn:

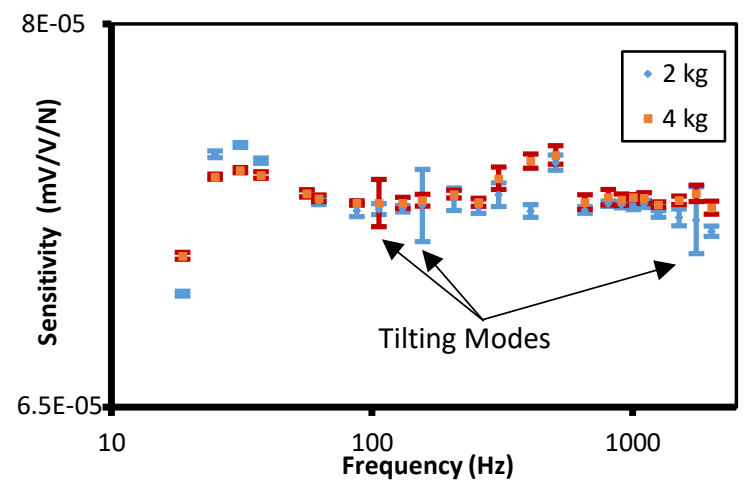

Figure 9. Typical dynamic sensitivity of a dynamic force transducer using two different load masses, 2 and $\mathrm{kg}$, with the corresponding expanded uncertainty of the individual sensitivity points. The results show the effect of the tilting modes on the resulting uncertainties.

a. A new numerical model of the complete mechanical structure was developed.

b. A good agreement between the simulated and measured results has been achieved. A deviation of only about $1.3 \%$ between the measured and simulated results has been observed.

c. The reasons for the small deviation in the simulated results may be due to using tabulated rather than measured material properties, the assumptions of boundary conditions, or the assumption of rigid connections.

d. Based on the given results, the tilting modes of the complete mechanical structure introduce a significant impact on the acceleration distribution over the load mass and hence on the expanded uncertainty.

e. The accuracy of the FE model can be enhanced through the inclusion of the damping properties.

\section{ACKNOWLEDGEMENT}

The authors gratefully acknowledge support from the Braunschweig International Graduate School of Metrology B-IGSM. The authors would also like to thank their colleague Holger Kahmann from PTB for his support in FEM using ANSYS software.

\section{REFERENCES}

[1] C. Schlegel, G. Kieckenap, B. Glöckner, A. Buß, R. Kumme, Traceable periodic force calibration, Metrologia 49, 3 (2012) pp. 224-235.

[2] N. Medina, J. de Vicente, Force sensor characterization under sinusoidal excitations, Sensors (Switzerland), 14, 10 (2014) pp. 18454-18473. Online [Accessed 20190912]: https://www.mdpi.com/1424-8220/14/10/18454/pdf

[3] N. Vlajic, A. Chijioke, Traceable dynamic calibration of force transducers by primary means, Metrologia, 53, 4 (2016) pp. S136S148.

[4] R. Kumme, Investigation of a primary method for a dynamic calibration of force measuring instruments: a contribution to reduce the measuring uncertainty, Doctoral Thesis, in German, PTB, 1996.

[5] C. Schlegel, G. Kiekenap, H. Kahmann, R. Kumme, Mechanical influences in sinusoidal force measurement, ACTA IMEKO, 4, 2 (2015), pp. 57-61. Online [Accessed 20190912]: http://dx.doi.org/10.21014/acta imeko.v4i2.206 
[6] M. Kobusch, S. Eichstädt, Challenges of the model-based dynamic calibration of force transducers - A case study, Proc. of the XXIst IMEKO World Congress, Prague, Czech Republic, 30 August - 4 September 2015. Online [Accessed 20190912]: https://www.imeko.org/publications/wc-2015/IMEKO-WC2015-TC3-053.pdf

[7] S. R. Hassan, C. Schlegel, R. Kumme, Mechanical influences of the shaker armature on periodic force measurement, Proc. of the IMEKO $23^{\text {rd }} \mathrm{TC} 3,13^{\text {th }}$ TC5 and $4^{\text {th }}$ TC22 Conferences, Helsinki, Finland, 30 May-1 June 2017. Online [Accessed 20190912]: https://www.imeko.org/publications/tc3-2017/IMEKO-TC32017-021.pdf
[8] C. Schlegel, G. Kieckenap, R. Kumme, Application of a scanning vibrometer for the periodic calibration of force transducers, Proc. of the $\mathrm{XX}^{\text {th }}$ IMEKO World Congress, Busan, Republic of Korea, 9-12 September 2012. Online [Accessed 20190912]: https://www.imeko.org/publications/wc-2012/IMEKO-WC2012-TC3-O8.pdf

[9] Ch. Schlegel, G. Kiekenap, R. Kumme, Uncertainty contributions in sinusoidal force measurement, Proc. of the IMEKO 22 $2^{\text {nd }}$ TC3, 12 $2^{\text {th }}$ TC5 and $3^{\text {td }}$ TC 22 International Conferences, Cape Town, South Africa, 3 - 6 February 2014. Online [Accessed 20190912]:

https://www.imeko.org/publications/tc3-2014/IMEKO-TC32014-014.pdf 